\title{
Spectral Analysis of Surface Wave for Empirical Elastic Design of Anchored Foundations
}

\author{
S. E. Chen ${ }^{1}$ and C. K. Ong ${ }^{2}$ \\ ${ }^{1}$ Department of Civil and Environmental Engineering, University of North Carolina at Charlotte, Charlotte, NC 28223, USA \\ ${ }^{2}$ Burns and McDonnell, Houston, TX 77027, USA
}

Correspondence should be addressed to S. E. Chen, schen12@uncc.edu

Received 6 July 2011; Revised 17 November 2011; Accepted 19 November 2011

Academic Editor: E. J. Sapountzakis

Copyright ( $) 2012$ S. E. Chen and C. K. Ong. This is an open access article distributed under the Creative Commons Attribution License, which permits unrestricted use, distribution, and reproduction in any medium, provided the original work is properly cited.

Helical anchors are vital support components for power transmission lines. Failure of a single anchor can lead to the loss of an entire transmission line structure which results in the loss of power for downstream community. Despite being important, it is not practical to use conventional borehole method of subsurface exploration, which is labor intensive and costly, for estimating soil properties and anchor holding capacity. This paper describes the use of an empirical and elasticity-based design technique coupled with the spectral analysis of surface wave (SASW) technique to provide subsurface information for anchor foundation designs. Based on small-strain wave propagation, SASW determines shear wave velocity profile which is then correlated to anchor holding capacity. A pilot project involving over 400 anchor installations has been performed and demonstrated that such technique is reliable and can be implemented into transmission line structure designs.

\section{Introduction}

Foundation is the load transfer mechanism from structure to the earth medium, and the design of foundations typically relies on the determination of soil strength, $Q_{u}$, which is then reduced by a safety factor, FS, to get the allowable stress, Qallowable:

$$
Q_{\text {allowable }}=\frac{Q_{u}}{\mathrm{FS}}
$$

The strength variables required may include cohesion and frictional angles of soil and various shape and load modification factors. Davis and Selvadurai [1] argued that the safety factors limit the behaviors to within the elastic range ( $1 / 3$ of peak stress). Hence, they suggested that there may be incidence where elastic foundation design would make sense. Since most soil/rock mechanical testing methods are associated with the determination of ultimate strengths of soil material, Davis and Selvadurai [1] further suggested using geophysical testing methods for determining in situ soil elastic parameters. While strong reasoning is presented, no real-life design examples were offered to reinforce the elastic design idea. Recent paper by Selvadurai [2] further extended the argument about the importance of elasticity in soil mechanics to poroelastic problems.

This paper identified power transmission structures as likely candidates for elastic-based design and suggests using an empirically based method for the elastic design of anchor foundations using a Rayleigh wave-based soil exploration technique for determining soil elastic parameters [3-5]. This approach is applied to anchor-supported transmission line structures, which are typically stabilized by helical anchors that are often installed without prior information on the underlying soil characteristics [3]. Because anchor holding capacity is dependent on the inherent resistance of soil, failure to analyze pertinent soil properties before transmission line construction could lead to disastrous anchor pullouts. Such failures may not only affect a specific transmission line structure but may also jeopardize the stability of neighboring transmission structures resulting in a domino failure mode that can cause extensive power outages for downstream communities. However, most transmission structures are erected in a rapid fashion without extensive subsurface explorations, and as a result, the anchors are usually installed with basic recommendations from the anchor manufacturer [4]. 
The proposed soil exploration technique, spectral analysis of surface waves (SASWs), is based on the detection of impact-induced, small-strain stress waves [5]. The method generates the shear wave velocity versus depth profiles of the tested soil and has been successfully applied to the detection of pavement thickness, characterization of shallow soil profiles, and correlation to soil liquefaction potentials [5-13]. Three technical data can be established using SASW: (1) recommended embedment depth of the anchors, (2) soil stiffness at the necessary depth, and (3) depth of bedrock. To correlate wave speed to anchor holding capacity, controlled pull tests were performed at different soil sites resulting in a linear correlation. Figure 1 shows the stress distribution of pulled anchors at different depth (after Niroumand and Kassim [14]). If sufficient safety factor is built in the design, such that the anchor system will be loaded in the elastic range, then the elastic soil parameters determined by SASW may be correlated to the actual anchor holding capacity. Figure 2 shows the schematic connection between elastic wave parameters and the ultimate anchor holding capacities for anchored structures. The correlation is established via actual geophysical and anchor pull tests at several test sites [15]. The empirical-based design approach is then validated using actual design and pull tests on transmission line in Georgia, USA.

\section{Conventional Anchor Foundation Constructions and Soil Exploration}

Helical anchor foundations are tension foundations using uplift capacity of anchor to resist pullout of the anchors [16-21]. Conventional design of anchored foundations for power transmission structures relies on soil ultimate strength parameters (cohesion, $c$, and frictional angle, $\Phi$ ) which are determined using in situ destructive soil exploration techniques such the standard penetration test (SPT) [21]. Niroumand et al. summarized past experimental data on the studies of anchor plates for different soils [14, 22]. This test is labor intensive and time consuming, and it requires extensive drilling and sampling at isolated points to measure a stiffness parameter known as the $N$-value, which may or may not be representative of the entire underlying area where the structure would be built. This scenario becomes a serious problem in areas with highly heterogeneous soils, especially at multilayered soil systems. The high cost and inherent inaccuracies of SPT necessitated current practices of installing anchors without soil exploration, which is a "hitor-miss" strategy that incorporates an anchor pull test.

In the anchor pull test, a helical anchor is usually installed until it reaches a specified torque rating or deformity [23]. Once installed, the anchor is then pulled by backing a bulldozer coupled to a dynamometer to measure the anchor holding capacity (Figure 3). Despite being time consuming, this strategy obviously circumvents the need to perform SPT. However, the anchors installed with this method are severely deformed; hence, its original properties may have been perturbed. Pulling on the anchor to perform the test may also disturb the surrounding areas where the other helical

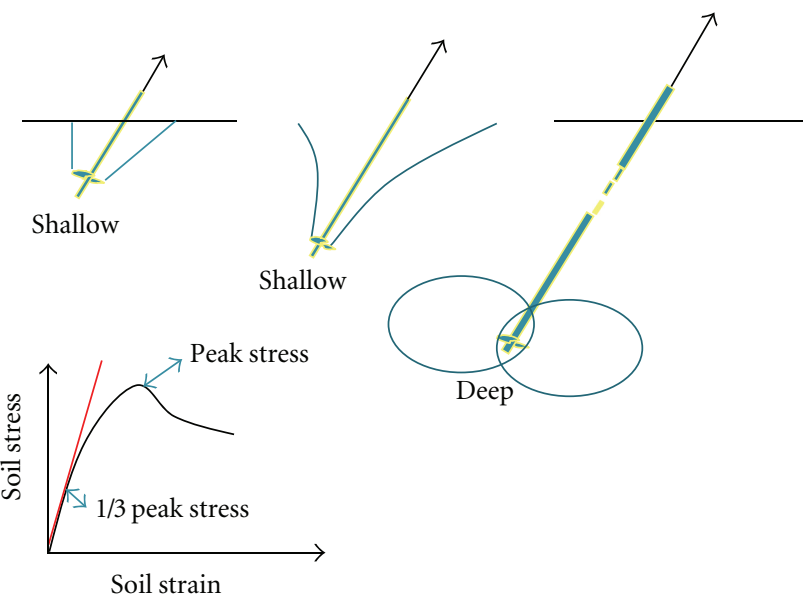

Figure 1: Basic assumption behind elasticity-based design (modified from Matthews [12]).

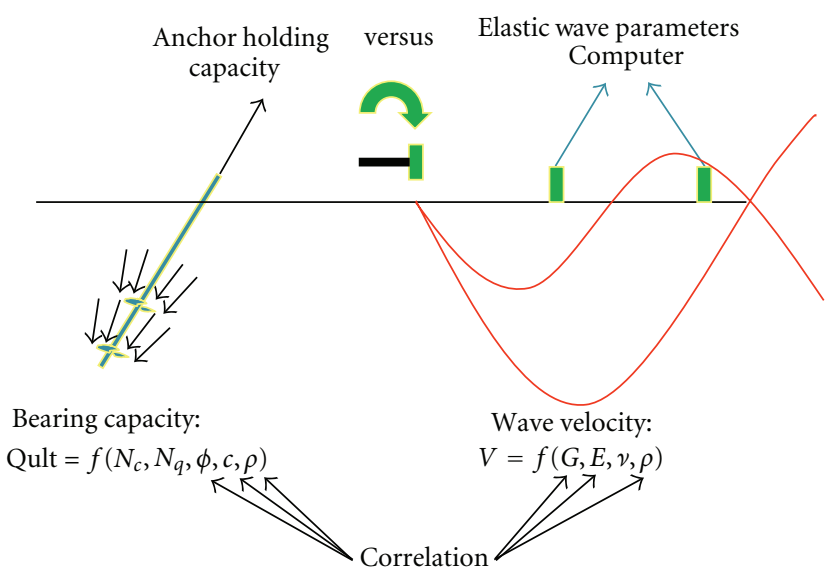

FIGURE 2: Correlation between anchor holding capacity and elastic wave parameters.

anchors are to be installed. Moreover, because the stiffness of the soil is unknown, anchor installation depth can vary from $3 \mathrm{~m}$ in sand to more than $30 \mathrm{~m}$ in swampy soil conditions. Such unpredictability can be expensive: instead of anchoring at $30 \mathrm{~m}$, prior soil exploration may reveal an area where anchoring can be accomplished at lesser depths, leading to the use of fewer extension rods. The relative hazard and unpredictability of this anchor pull test approach, as well as the drawbacks of SPT, warrant the development of inexpensive, nondestructive, and accurate means to measure soil stiffness.

\section{Spectral Analysis of Surface Waves}

Survey of potential nondestructive, geophysical testing methods suggested that spectral analysis of surface waves (SASWs) offers a viable alternative for measuring soil stiffness [3]. By subjecting soil to a propagating impact wave, a characteristic shear wave velocity is generated. This shear wave velocity is a function of the elastic properties of the soil; hence, 


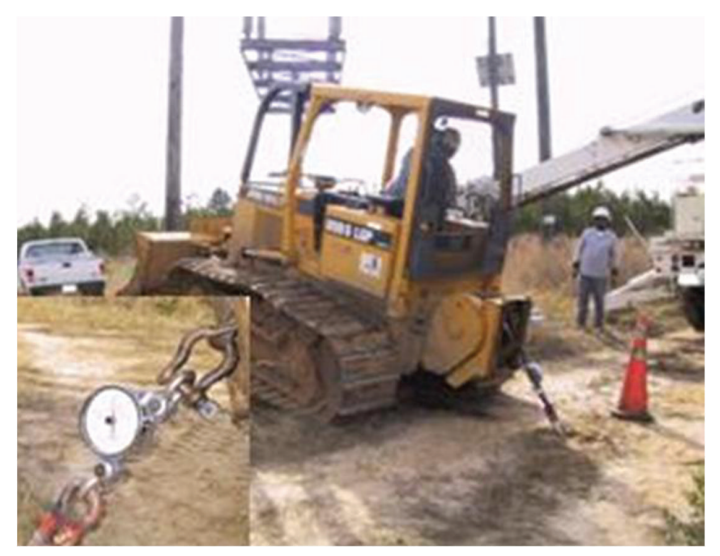

Figure 3: Bulldozer coupled with dynamometer to measure anchor holding capacity.

this technique may provide a descriptive profile of soil stiffness with depth. The theoretical shear wave velocity profile, obtained through such a process, corresponds to the maximum shear modulus at small strains of the test site. Figure 4 shows the effect of strain magnitude effect on shear modulus in a typical shear stress, $\tau$, versus shear strain, $\gamma$, curve. Strain rate of $0.05 \%$ is typically defined as small strain rate [24]. The method consists of three phases: (1) field testing and data collection, (2) evaluation of the field Rayleigh wave dispersion curve, and (3) inversion of the dispersion curve to obtain the shear wave velocity profile. SASW testing involves a mechanical excitation (i.e., hammer impact) and two low-frequency receivers. During testing, the two receivers are placed on the soil surface such that the distance from the impact source to the first receiver (D) is equal to the distance between the two receivers (D), which is a function of the wavelength of the excited waves. These receivers are connected to a data acquisition system. Using impact excitation, small-strain stress waves with a broad spectral content are generated which when passing through the equally spaced receivers would allow corelatable signals to be captured. Testing is typically performed in both forward and reverse directions in order to generate an average dispersion curve. General configuration for SASW testing setup is shown in Figure 5.

Also shown in Figure 5 is the idea that widening sensor spacing generates deeper waves and hence detects soil properties at deeper soils. The spacing of these two sensors $(L)$ is equal to the distance between the impact source to the nearest receiver. Each recorded time series signal from the receivers is transformed into frequency domain by the Fourier transformation. After each test, the frequency spectrums from the two receivers are then compared to determine the phase angle shifts at different frequencies. The phase difference between two signals is then determined, and the travel time $(t)$ between the two receivers at each frequency can be obtained as [25]

$$
t=\frac{\varnothing}{2 \pi f}
$$

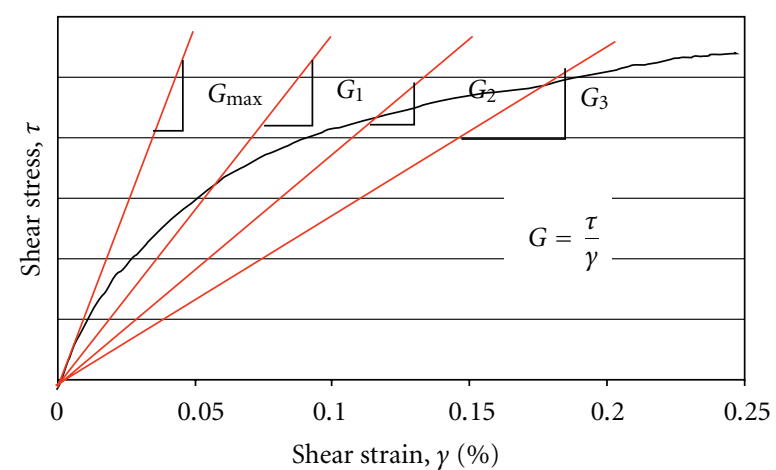

FIGURE 4: Change in shear moduli at different levels of shear strain $[10,11]$.

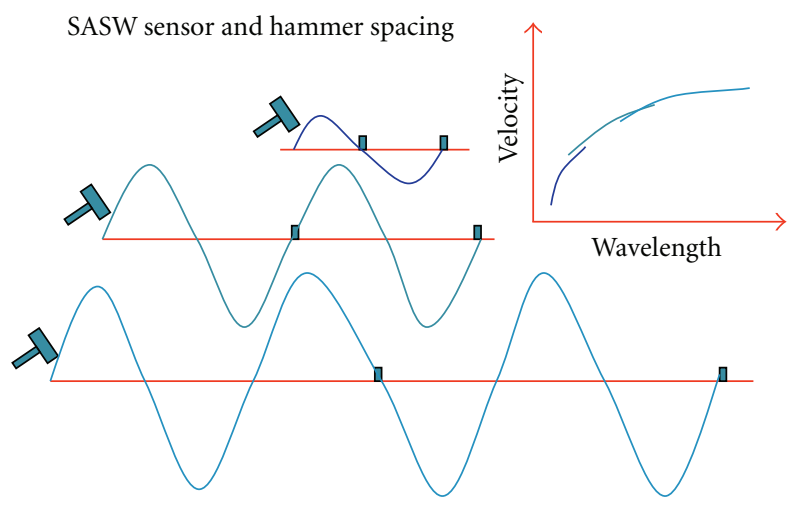

FIGURE 5: SASW test setup and sensor spacing arrangements.

where $\varnothing$ is phase difference at a given frequency $f$. The surface wave velocity $\left(V_{s}\right)$ can be obtained from (3), where $L$ is distance between the two receivers

$$
V_{s}=\frac{L}{t}
$$

The corresponding wavelength $(\lambda)$ is then determined as

$$
\lambda=\frac{V_{s}}{f} .
$$

Calculations are performed at each frequency component and result in dispersion curves. These dispersion curves are then used to determine the theoretical shear wave velocity profile through an iterative process of matching the experimental dispersion curve to the assumed theoretical shear wave velocity curve [25]. The layering of the site and shear wave velocity of each layer was assumed based on the experimental dispersion curve.

For the anchor foundation study, different size hammers and $4 \mathrm{~Hz}$ geophones have been used for the ground vibration sensing. The tests were conducted at spacing ranging between $0.5 \mathrm{~m}, 1.0 \mathrm{~m}, 1.8 \mathrm{~m}, 3.6 \mathrm{~m}, 7.3 \mathrm{~m}$, and $14.6 \mathrm{~m}$. At each location, more than 5 hits were conducted, and the average signal is then used. 


\section{Anchor Holding Capacity Correlation}

Since the anchor holding capacity, $Q_{\text {ult }}$, is a function of the ultimate strength parameters, $c$ and $\Phi$, material density, $\rho$, and strength modification factors, $N_{c}$ and $N_{q}$, and so forth [26]. Equation (5) through (7) shows the uplift capacity of an anchor in sand, silt, and clay, respectively:

$$
\begin{aligned}
Q_{\mathrm{ult}}= & \pi \gamma^{\prime} K_{u} \tan \varphi \cos ^{2} \frac{\varphi}{2}\left[\left(\frac{D_{1} H_{1}^{2}}{2}\right)+\left(\frac{H_{1}^{3} \tan (\varphi / 2)}{3}\right)\right] \\
& +\left(\frac{\pi}{2}\right) D_{a} \gamma^{\prime}\left(H_{3}^{2}-H_{1}^{2}\right) K_{u} \tan \varphi+W_{s}
\end{aligned}
$$

$$
\begin{aligned}
Q_{\text {ult }}= & \gamma^{\prime} H_{1} A_{1} N_{q u}+A_{1} c N_{c u}+\left(\frac{\pi}{2}\right) D_{a} \gamma^{\prime}\left(H_{3}^{2}-H_{1}^{2}\right) K_{u} \tan \varphi^{\prime} \\
& +\pi D_{a} c\left(H_{3}-H_{1}\right)+P_{s} H_{1}\left(\frac{\gamma^{\prime}}{2}\right) H_{1} K_{u} \tan \varphi^{\prime}+P_{s} H_{1} C_{a},
\end{aligned}
$$

$Q_{\text {ult }}=A_{1} c N_{c u}+\pi D_{a} c\left(H_{3}-H_{1}\right)+P_{s} H_{1} C_{a}$,

where

$$
\begin{aligned}
Q_{\mathrm{ult}} & =\text { ultimate anchor uplift capacity }(\mathrm{lb}), \\
\gamma^{\prime} & =\text { effective unit weight of soil }\left(\mathrm{lb} / \mathrm{ft}^{3}\right), \\
H_{1} & =\text { depth to top of helix }(\mathrm{ft}), \\
N_{q u} & =\text { uplift capacity factor for cohesionless soils (unit- } \\
& \text { less), } \\
D_{a} & =\text { average helix diameter }(\mathrm{in} .), \\
H_{3} & =\text { depth to bottom of helix }(\mathrm{ft}), \\
K_{u} & =\text { coefficient of lateral earth pressure in uplift for } \\
& \text { cohesionless soil (unitless), } \\
P_{s} & =\text { perimeter of anchor shaft (in.), } \\
C_{a} & =\text { adhesion on anchor shaft (unitless), } \\
A_{1} & \left.=\text { area of top helix (in. }{ }^{2}\right), \\
\varphi & \left.=\text { internal friction angle for cohesionless soil ( }{ }^{\circ}\right), \\
\varphi^{\prime} & \left.=\text { internal friction angle for cohesive soil ( }{ }^{\circ}\right), \\
N_{c u} & =\text { uplift capacity factor for cohesive soil (unitless), } \\
c & =\text { cohesion at helix plate }\left(\mathrm{lb} / \mathrm{ft}^{2}\right), \\
W_{s} & =\text { weight of soil in failure zone }(\mathrm{lb}) .
\end{aligned}
$$

Kulhawy et al. stated that all anchors behave in the same basic manner and listed the following failure modes: (1) the cone resistance failure mode assumes that the uplift resistance is provided by the weight of the soil within the cone of anchor; (2) the shear failure mode assumes that a failure occurs along a cylindrical shear surface; (3) the bearing capacity failure mode assumes that a cavity forms above the bottom plate or helix, providing the failure surface [16]. Niroumand et al. $[14,22]$ showed that the stress distribution is actually a function of embedment depth and can be differentiated into shallow and deep anchors (Figure 1).

The complexity of (5) and the rapid construction of anchored foundations warrant simplified and quick design
TABLE 1: Typical Shear Wave Velocities [22].

\begin{tabular}{lc}
\hline Soil classification & Shear wave velocity $(\mathrm{m} / \mathrm{sec})$ \\
\hline Very soft soil & $84-106$ \\
Soft soil & $107-137$ \\
Medium soil & $138-183$ \\
Stiff Soil & $184-274$ \\
Very stiff soil & $275-366$ \\
Soft rock/cemented soil & $367-610$ \\
Rippability limit & 670 \\
Rock & $>670$ \\
Concrete & $2,286-2,438$ \\
\hline
\end{tabular}

TABLE 2: Selected anchor pull test results.

\begin{tabular}{lccc}
\hline Anchor number & Depth $(\mathrm{m})$ & $\begin{array}{c}\text { Torque/no } \\
\text { torque }\end{array}$ & $\begin{array}{c}\text { Pull load to failure } \\
(\mathrm{kN})\end{array}$ \\
\hline T1 & 4.3 & No torque & 133.5 \\
T2 & 5.2 & No torque & 177.9 \\
T3 & 7.3 & No torque & 222.4 \\
T4 & 9.1 & Torque & 355.9 (held) \\
T5 & 2.1 & No torque & 133.5 \\
T6 & 9.8 & Torque & 355.9 (held) \\
T7 & 9.8 & Torque & 355.9 (held) \\
T8 & 6.4 & Torque & $334.5($ held) \\
T9 & 7.3 & No torque & 111.7 \\
T10 & 9.1 & No torque & 197.9 \\
T11 & 13.7 & Refusal & 117.2 \\
T12 & 14.9 & Refusal & 83.8 \\
T13 & 15.8 & Refusal & 93.4 \\
T14 & 3.0 & No torque & 191.7 \\
T15 & 3.0 & No torque & 191.7 \\
T16 & 3.7 & No torque & 244.7 \\
T17 & 5.2 & Torque & 244.7 \\
T18 & 5.8 & Refusal & 99.6 \\
T19 & 5.5 & Refusal & 169.0 \\
\hline
\end{tabular}

approaches [15]. However, the propagating wave velocities, $V$, are functions of elastic material constant, $G$ (shear modulus), $E$ (Young's modulus), $v$ (Poisson's ratio), and material density, $\rho$. The elastic design approach assumes that the wave velocity and holding capacity can be correlated, since at small strain, soil does not show any degradation of stiffness both with strain level and with loading/unloading cycles, and linear elastic model is a good approximation.

To establish the correlation between shear wave velocities and anchor holding capacity, a total of 62 SASW tests, 29 soil boring with SPT, and 97 anchors pull tests were conducted throughout southeastern parts of the United States. The test anchors were installed at different depths and stiffness (determined by SASW), and pull tests were conducted to determine their holding capacity [27]. The soil stiffness and condition from the SASW were also validated with SPT data. Two types of anchors were investigated at this project 


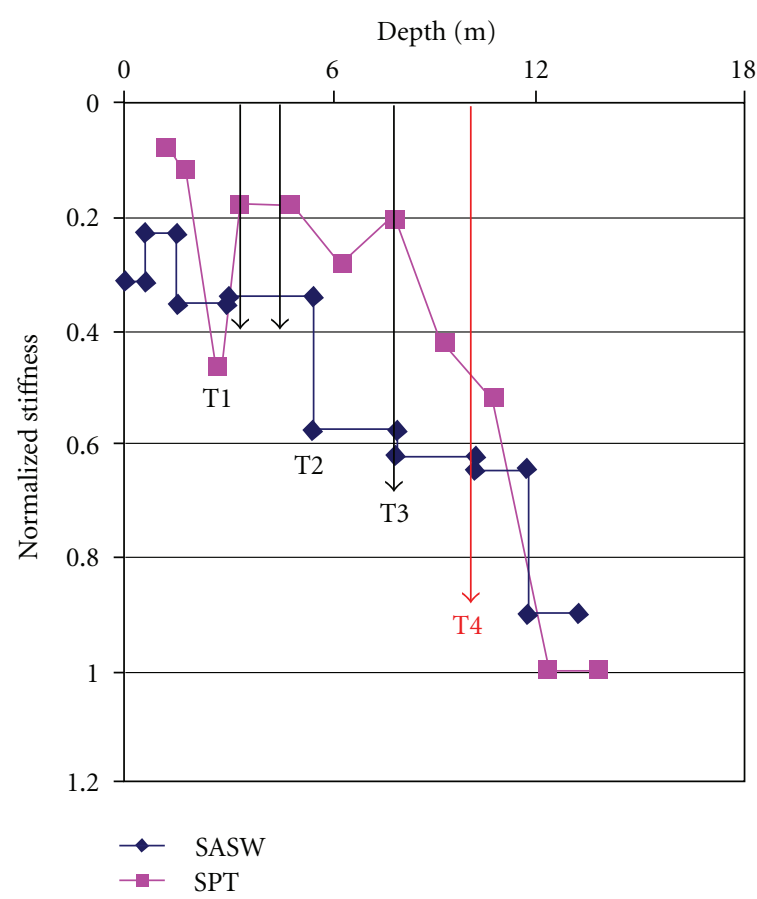

(a) Location 1 in Alabama

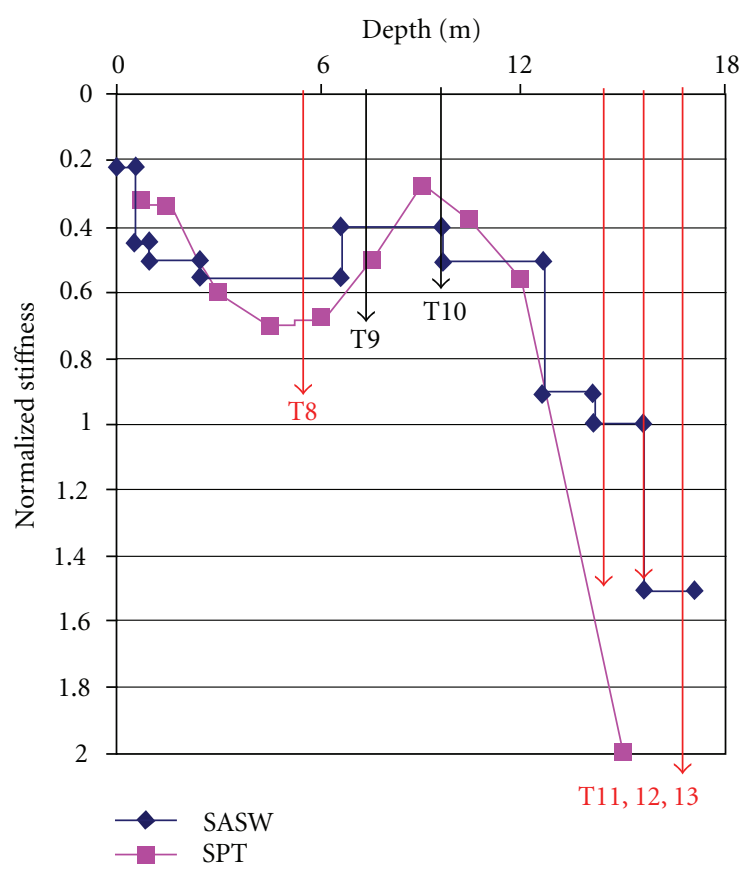

(c) Location 1 in Georgia

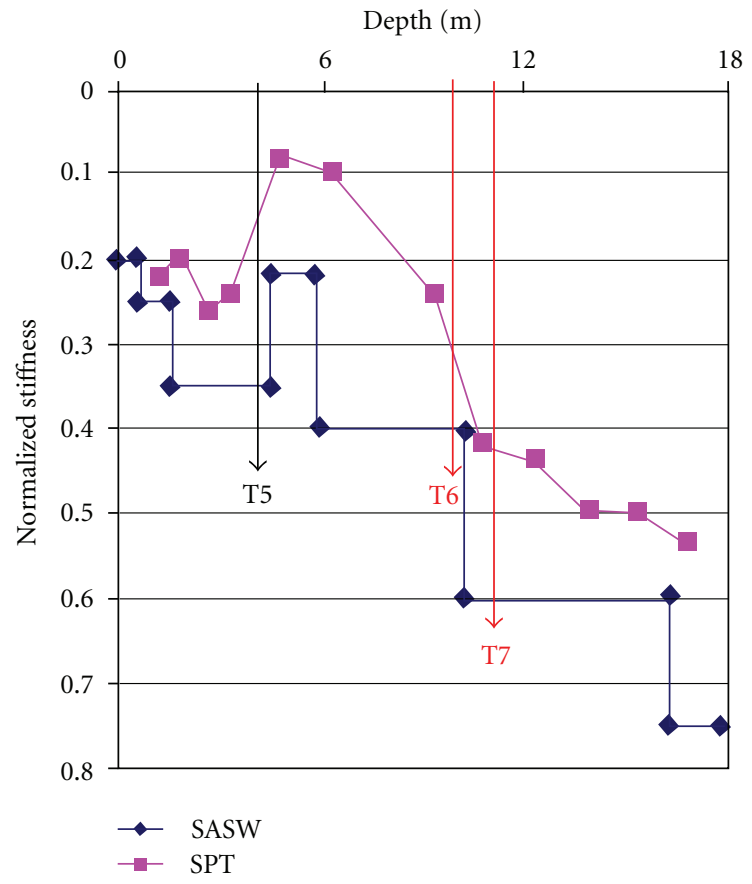

(b) Location 2 in Alabama

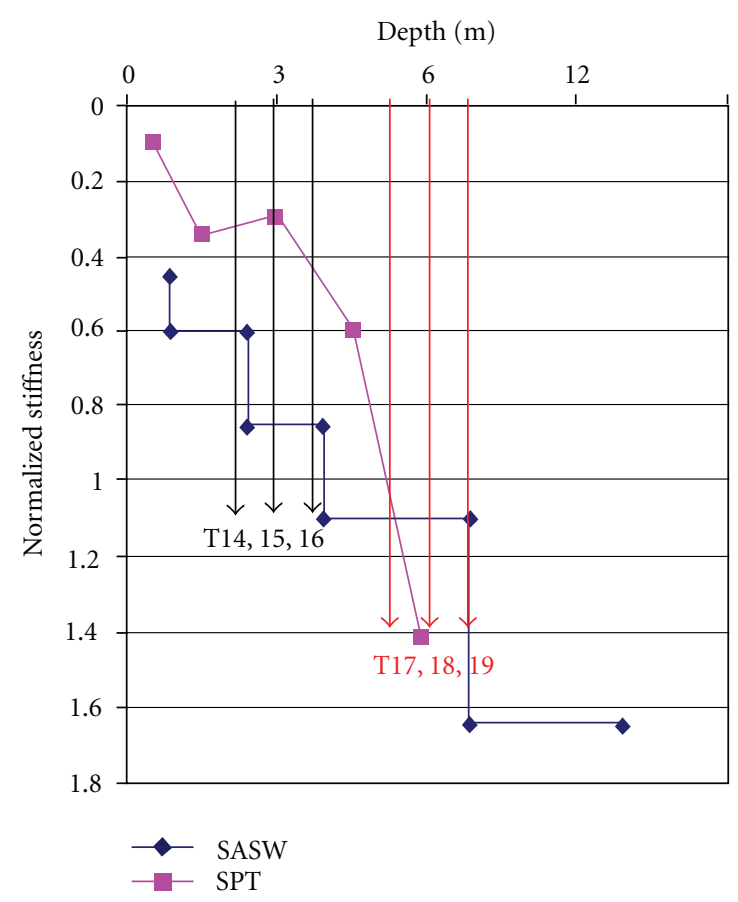

(d) Location 2 in Georgia

FIGURE 6: Field tests results (SASW, SPT, and anchor pull tests).

(torsion capacities of $6.78 \mathrm{kN}-\mathrm{m}$ and $9.49 \mathrm{kN}-\mathrm{m}$ ). These anchors are the ones most frequently used by the power companies.

Selected results are plotted in Figure 6, which represent the comparison of SASW shear wave velocity and SPT $N$ - values. These values represent normalized stiffness between the two parameters where shear wave velocity was divided by $670 \mathrm{~m} / \mathrm{sec}$ (typical shear wave velocity for rock (Table 1 [24])), and $N$-values were divided by 50 (auger refusal). It is also shown in Figure 6 and marked with arrows for T1 


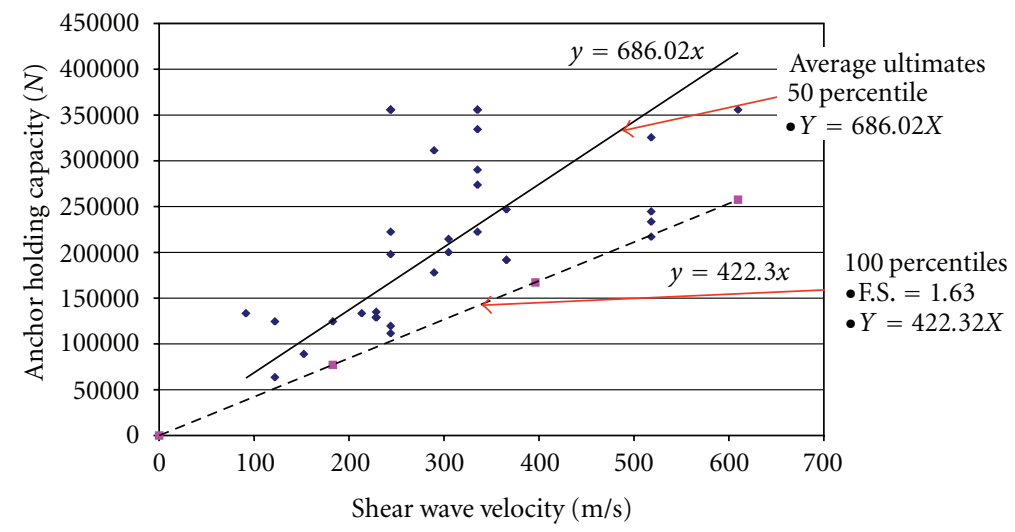

FIGURE 7: Anchor holding capacity versus shear wave velocity with 50 percentile and 100 percentile linear correlations.

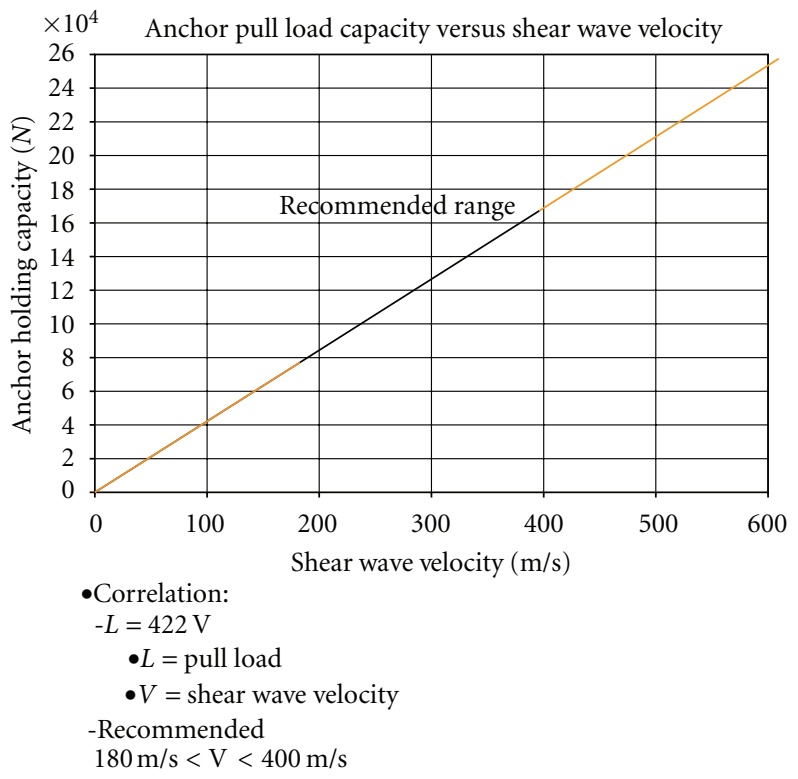

FIGURE 8: Recommended range for anchor pull load capacity versus shear wave velocity.

through T19 anchors that were installed to respective depths. Table 2 shows the representative anchor pull tests results. All anchors were subjected to pull to failure or $356 \mathrm{kN}$. Failure indicates that the anchor has a total creep of more than $100 \mathrm{~mm}$ [27].

Based on all the collected anchor pull test data, a linear trend line is plotted in Figure 7 to show an average pull load capacity versus shear wave velocity with a linear equation of

$$
L=686.02 V_{S}
$$

where $\mathrm{L}=$ anchor - holding capacity $(\mathrm{lb})$ and $V_{S}=$ shear wave velocity $(\mathrm{ft} / \mathrm{sec})$.

However, it should be noted that the correlation has a very low $R^{2}$ value (0.1393). This low statistical fit may be due to the fact that the correlation does not differentiate between cohesive or frictional soils.

Because this equation is based on the average results, safety factors of different ranges are added to (8) to determine variations of anchor holding capacity versus shear wave velocity. This addition is to ensure that all the anchors will meet the minimum holding capacity. Figure 7 shows the variations of anchor holding capacity at different factors of safety. Equation (9) shows the calculation for a safety factor (FS) of 1.63, which is the maximum passing safety factor for the one-hundred-percentile linear regression line. The line will meet a minimum holding capacity from the collected test results

$$
\text { S.F. }=\frac{\text { Ultimate }_{\mathrm{AVG}}}{\text { Allowable }}=\frac{686.02}{422.32}=1.63
$$

The following equation shows the factored correlation between the anchors holding capacity versus shear wave velocity:

$$
L=422 V_{S} .
$$

Figure 8 shows the line for (10), in which the center range represents a recommended range (180 to $400 \mathrm{~m} / \mathrm{sec}$ ) for 
TABLE 3: Summarized of anchor installation and anchor pull tests at the recent pilot tests.

\begin{tabular}{|c|c|c|c|c|c|c|}
\hline \multirow{2}{*}{$\begin{array}{l}\text { Transmission structure } \\
\text { no. }\end{array}$} & \multicolumn{3}{|c|}{ Anchor installation } & \multicolumn{3}{|c|}{ Anchor pull tests } \\
\hline & Anchor installed & Installed to predicted depth & Twist prior to recommendation depth & Total & Passed & Failed \\
\hline 1 & 20 & 20 & 0 & 6 & 6 & 0 \\
\hline 2 & 13 & $\mathrm{~N} / \mathrm{A}$ & N/A & 6 & 6 & 0 \\
\hline 3 & 12 & 12 & 0 & 6 & 6 & 0 \\
\hline 4 & 16 & 16 & 0 & 9 & 9 & 0 \\
\hline 5 & 20 & 20 & 0 & 9 & 9 & 0 \\
\hline 6 & 20 & 16 & 4 & 8 & 8 & 0 \\
\hline 7 & 24 & 23 & 1 & 10 & 10 & 0 \\
\hline 8 & 20 & 17 & 3 & 8 & 8 & 0 \\
\hline 9 & 12 & 11 & 1 & 0 & 0 & 0 \\
\hline 10 & 20 & 17 & 3 & 8 & 8 & 0 \\
\hline 11 & 20 & 20 & 0 & 12 & 12 & 0 \\
\hline 12 & 18 & 18 & 0 & 0 & 0 & 0 \\
\hline 13 & 16 & 15 & 1 & 0 & 0 & 0 \\
\hline 14 & 20 & 13 & 7 & 0 & 0 & 0 \\
\hline 15 & 20 & 17 & 3 & 9 & 9 & 0 \\
\hline 16 & 18 & 18 & 0 & 8 & 8 & 0 \\
\hline 17 & 24 & 24 & 0 & 12 & 12 & 0 \\
\hline 18 & 20 & 20 & 0 & 12 & 12 & 0 \\
\hline 19 & 20 & 19 & 1 & 14 & 14 & 0 \\
\hline 20 & 24 & 24 & 0 & 8 & 8 & 0 \\
\hline 21 & 24 & 20 & 4 & 0 & 0 & 0 \\
\hline 22 & 16 & N/A & N/A & 0 & 0 & 0 \\
\hline 23 & 10 & 10 & 0 & 4 & 4 & 0 \\
\hline 24 & 12 & 12 & 0 & 5 & 5 & 0 \\
\hline Total & 439 & 382 & 28 & 154 & 154 & 0 \\
\hline Percentage & & 93.17 & 6.83 & & 100 & 0 \\
\hline
\end{tabular}

anchors to be installed. If an anchor is to be installed below at $<180 \mathrm{~m} / \mathrm{sec}$, the soil strength at this region may not provide a sufficient or minimum amount of holding capacity. This recommended range is to satisfy the requirement by the Southern Company that all anchors are installed at a minimum holding capacity of $75 \mathrm{kN}$ of working load. On the other hand, if the anchor is installed at $>400 \mathrm{~m} / \mathrm{sec}$, rock fragments may be encountered and cause refusal (unable to penetrate and does not torque out). As a result, an anchor must be installed with caution, especially outside the range represented by the bold black line.

Figure 9 shows a summary of the design approach where SASW testing technique determines the soil stiffness profile and based on (10), the embedment depth and the pull capacity can be determined. Using Table 1, it is also possible to project depth to bedrock using the wave velocity value. Since the soil testing technique determines elastic soil parameters, the method is considered as an elastic design. Aside from being totally nondestructive, the SASW technique is also rapid, relatively easy to perform, portable, and inexpensive.

\section{Field Validation Test}

A full-scale field validation testing was conducted in Georgia, USA, to verify the correlation of anchor holding capacity prediction based on the SASW results. The site is intended or an operating transmission line between Covington and Eatonton, GA. Figure 10 shows the extent of the validation project site. Based on field SASW tests and (10), a set of recommendations for anchor installation was provided, which included (1) soil stiffness versus depth; (2) number of extensions required for each anchor to be installed to desire depth.

A total of 439 anchors were installed for the transmission line, which all are installed according to the recommendations. Table 3 summarized anchor installation and anchor pull tests results. $93.17 \%$ of a total anchor installed reached recommended depths and only $6.83 \%$ (28 anchors) torque out prior to reaching recommended depths. Among those anchors, which reached full torque before reaching recommended depth, $82 \%$ (23 anchors) of them lacked one extension. A total of 154 pull tests up to either $71 \mathrm{kN}$ or $85 \mathrm{kN}$ 


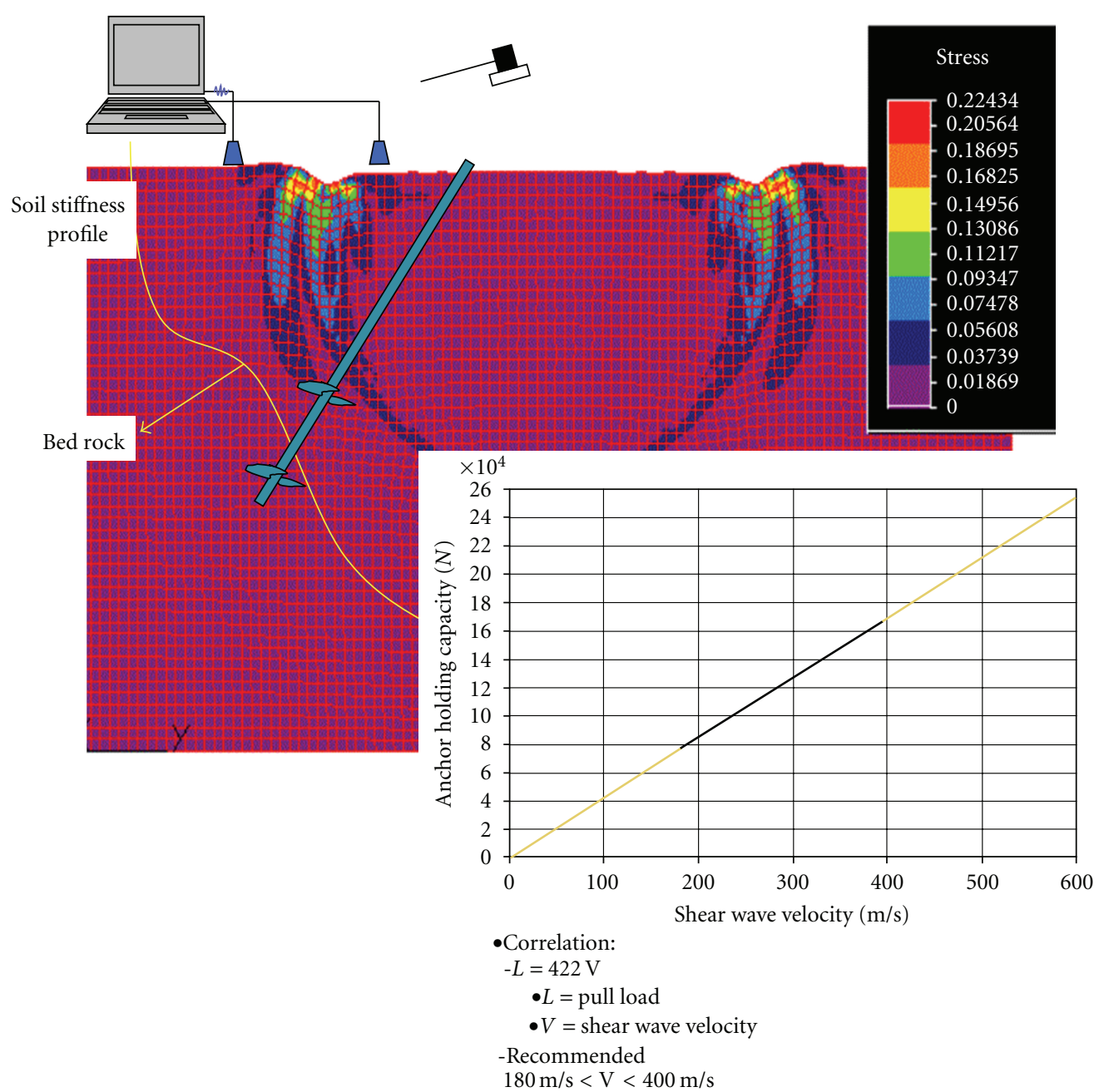

FIGURE 9: Elastic design of anchors based on surface wave soil testing.

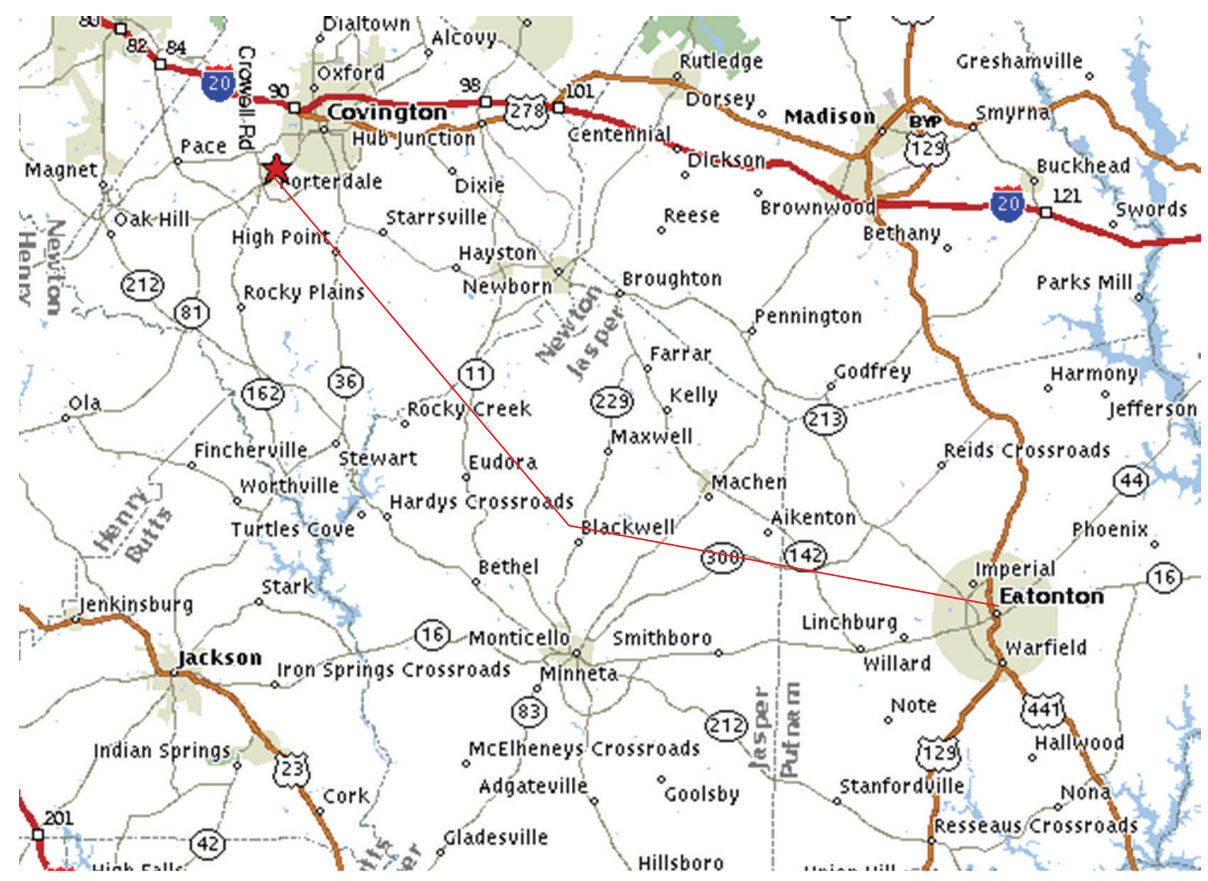

FIGURE 10: Validation project site in Georgia, USA. 
were conducted on these selected anchors. These loads are based on ultimate working loads. All anchors tested sustained the ultimate working pull load without failure.

\section{Conclusion}

An empirical-based elastic design approach for anchored foundation for transmission line structures is proposed in this paper. The design method relies on the use of elastic soil properties derived from SASW soil testing method, which is nondestructive and easy to perform and predicts the embedment depth and holding capacities of the buried anchors. The results of this study show that SASW testing can provide reliable prediction of depth to bedrock, and the correlated soil strengths and holding capacities of the anchors have been validated with anchor pull tests. A recently completed pilot project has demonstrated that such technique is reliable and can be implemented into transmission line structure designs.

SASW is valuable as an engineering tool for rapid geotechnical investigation since it identifies soil stiffness profile and has excellent correlation to SPT values $[12,13]$. It has also been used for detection of soil anomalies including hardpan layer, bedrock, and sinkholes. However, the poor statistical fit for the derived anchor holding capacity and shear wave speed correlation indicates that there needs to be further investigations of the relationship between elastic soil properties and foundation ultimate capacity. It also should be cautioned that elastic methods do not account for soil conditions change throughout the life of the structure, which may pose great limitations on where the technique may be applicable.

\section{Acknowledgments}

This research project is the result of financial sponsorship and technical support from the Southern Company. The researchers would like to first acknowledge Mr. Colby Galloway for his support and patience and the many engineers that have participated in and contributed to this research: Gentlemen from the Southern Company transmission line design/pole committee, Dennis E. Mize, Charles G. Munden Jr, Randy Pike, Brett Luebke, and Steve Roberts. The authors also like to acknowledge Professor Norbert Delatte of Cleveland State University and Mr. James Hightower for their technical contributions towards this study.

\section{References}

[1] R. O. Davis and A. P. S. Selvadurai, Elasticity and Geomechanics, Cambridge University Press, New York, NY, USA, 1996.

[2] A. P. S. Selvadurai, "The analytical method in geomechanics," Applied Mechanics Reviews, vol. 60, no. 3, pp. 87-106, 2007.

[3] N. Delatte and J. G. Hightower, "Feasibility study of improving the field prediction of helical anchor capacity," Tech. Rep., Alabama Power, Birmingham, Ala, USA, 1999.

[4] A.B. Chance Company, Encyclopedia of Anchoring, Hubbell/ Chance, Centralia, Mo, USA, 1999.

[5] S. Nazarian, K. H. Stokoe II, and W. R. Hudson, "Use of spectral analysis of surface waves method for determination of moduli and thicknesses of pavement systems," Transportation Research Record, no. 930, pp. 38-45, 1983.

[6] R. D. Andrus and K. H. Stokoe II, "A liquefaction evaluation procedure based on shear wave velocity," in Proceedings of the 31st Joint Meeting of the U.S.-Japan Cooperative Program in Natural Resources Panel on Wind and Seismic Effects, pp. 469474, Tsukuba, Japan, May 1999.

[7] N. Gucunski and R. D. Woods, "Instrumentation for SASW testing," Geotechnical Special Publication, no. 29, pp. 1-16, 1991.

[8] S. Nazarian, M. Baker, D. Yuan, and K. Crain, "Userfriendly surface wave method for integrity evaluation," in Nondestructive Evaluation of Aging Structures and Dams, vol. 2457 of Proceedings of SPIE, pp. 89-100, June 1995.

[9] K. H. Stokoe II, J. A. Bay, R. D. Andrus, and R. M. Chung, "Delineation of densified sand at treasure island by SASW testing," in Geotechnical Site Characterization, P. K. Robertson and P. W. Mayne, Eds., pp. 459-464, Balkema, Rotterdam, The Netherlands, 1998.

[10] K. H. Stokoe II, S. G. Wright, J. A. Bay, and J. M. Roesset, "Characterization of geotechnical sites by SASW method," in Proceedings of the 13th International Conference on Soil Mechanic and Foundation Engineering, Technical Report: Geophysical Characterization Of Sites, New Delhi, India, January 1994.

[11] D. S. Kim, M.-K. Shin, and H. C. Park, "Evaluation of density in layer compaction using SASW method," Soil Dynamics and Earthquake Engineering, vol. 21, no. 1, pp. 39-46, 2001.

[12] M. C. Matthews, V. S. Hope, and C. R. I. Clayton, "The geotechnical value of ground stiffness determined using seismic methods," Engineering Geology Special Publications, vol. 12, pp. 113-123, 1997.

[13] R. D. Andrus, P. Piratheepan, B. S. Ellis, J. Zhang, and C. H. Juang, "Comparing liquefaction evaluation methods using penetration-VS relationships," Soil Dynamics and Earthquake Engineering, vol. 24, no. 9-10, pp. 713-721, 2004.

[14] H. Niroumand and K. A. Kassim, "Experimental study of horizontal anchor plates in cohesionless soils," Electronic Journal of Geotechnical Engineering, vol. 15, pp. 609-620, 2010.

[15] C. K. Ong, S. E. Chen, C. Galloway, and N. Delatte, "Correlating spectral analysis of surface waves (SASW) technique to anchor holding capacity," in Proceedings of the Structural Materials Conference V-An NDT Conference, ASNT, Buffalo, NY, USA, 2004.

[16] J. I. Adams and D. C. Hayes, "The uplift capacity of shallow foundations," Ontario Hydro Research Quarterly, vol. 19, no. 1, pp. 1-13, 1967.

[17] Dames and Moore, "Pullout tests on multi-helix screw anchors," Report, Virginia Electric Power Company, Shacklefords, Va, USA, 1980.

[18] S. P. Clemence, The Uplift and Bearing Capacity of Helix Anchors in Soil, Vols. 1, 2 and 3, Syracuse University, Syracuse, 1984.

[19] J. S. Mooney, S. Adamczak, and S. P. Clemence, "Uplift capacity of helical anchors in clay and silt," in Uplift Behavior of Anchor Foundations in Soil, pp. 48-72, ASCE, New York, NY, USA, 1985.

[20] B. M. Das, "A procedure for estimation of ultimate capacity of foundations in clay," Soils and Foundations, vol. 20, no. 1, pp. 77-82, 1980.

[21] B. M. Das, Earth Anchors, Elsevier, Amsterdam, The Netherlands, 1990. 
[22] H. Niroumand, K. A. Kassim, and R. Nazir, "Experimental studies on horizontal anchor plates in cohesive soil," Electronic Journal of Geotechnical Engineering, vol. 15, pp. 879-886, 2010.

[23] R. M. Hoyt and S. P. Clemence, "Uplift capacity of helical anchors in soils," Bulletin 02-9001, AB Chance, Centralia, 1989.

[24] J. Bay, Site Characterization Using the Spectral Analysis Of Surface Waves (SASW) Method, Lecture notes, Two-Day SASW Short Course, University of Alabama, Birmingham, Ala, USA, 2002.

[25] C. G. Lai and K. Wilmanski, Surface Waves in Geomechanics: Direct and Inverse Modelling for Soils and Rocks, Springer, New York, NY, USA, 2005.

[26] F. H. Kullhawy, "Uplift behavior of shallow soil anchor," in Uplift Behavior of Anchor Foundations in Soil, S. P. Clemence, Ed., pp. 1-25, ASCE, New York, NY, USA, 1985.

[27] S. E. Chen, C. K. Ong, C. K. Galloway, and N. Delatte, "Applications of surface wave testing for stability determination of earth-bound structures," Experimental Techniques, vol. 31, no. 4, pp. 20-24, 2007. 

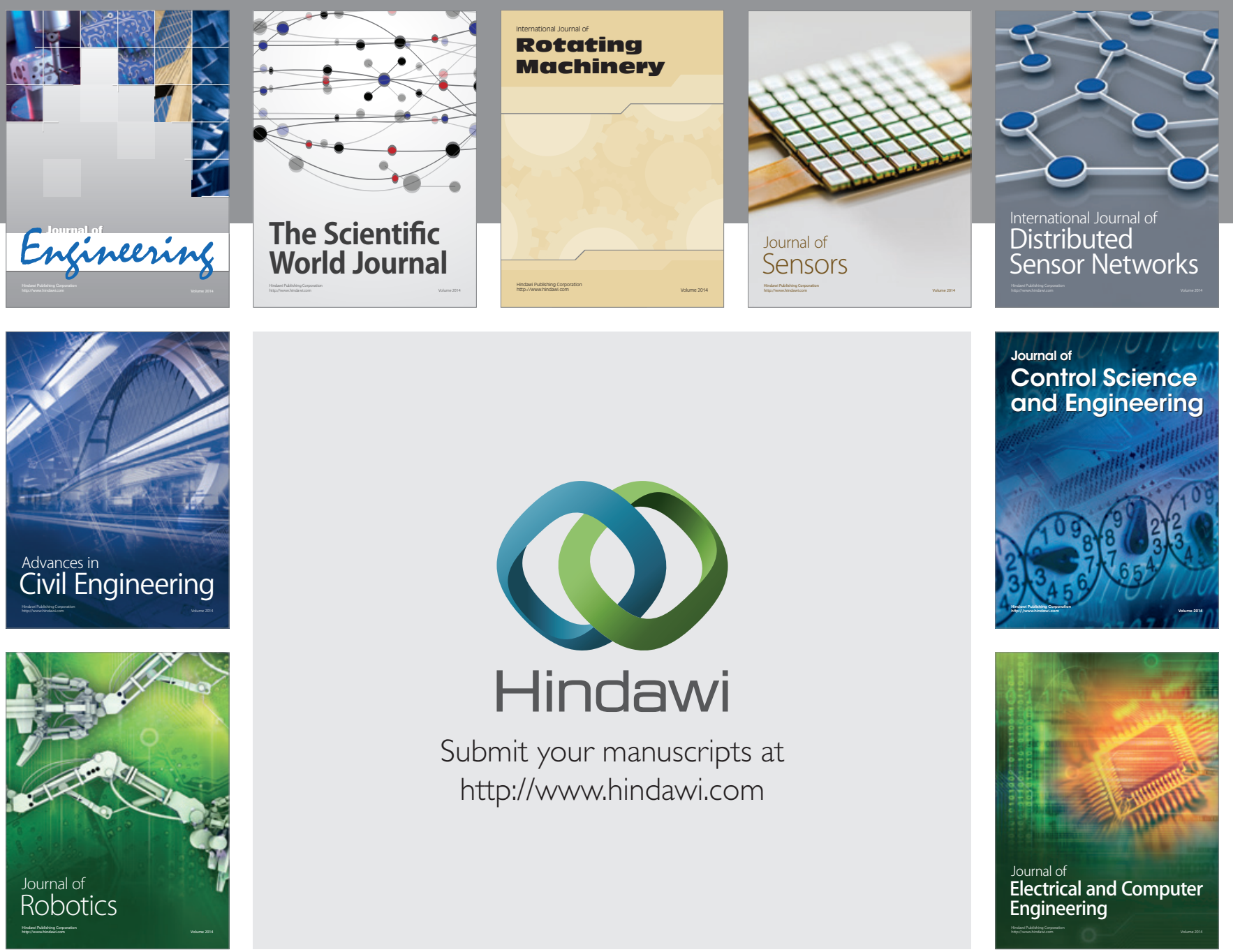

Submit your manuscripts at

http://www.hindawi.com
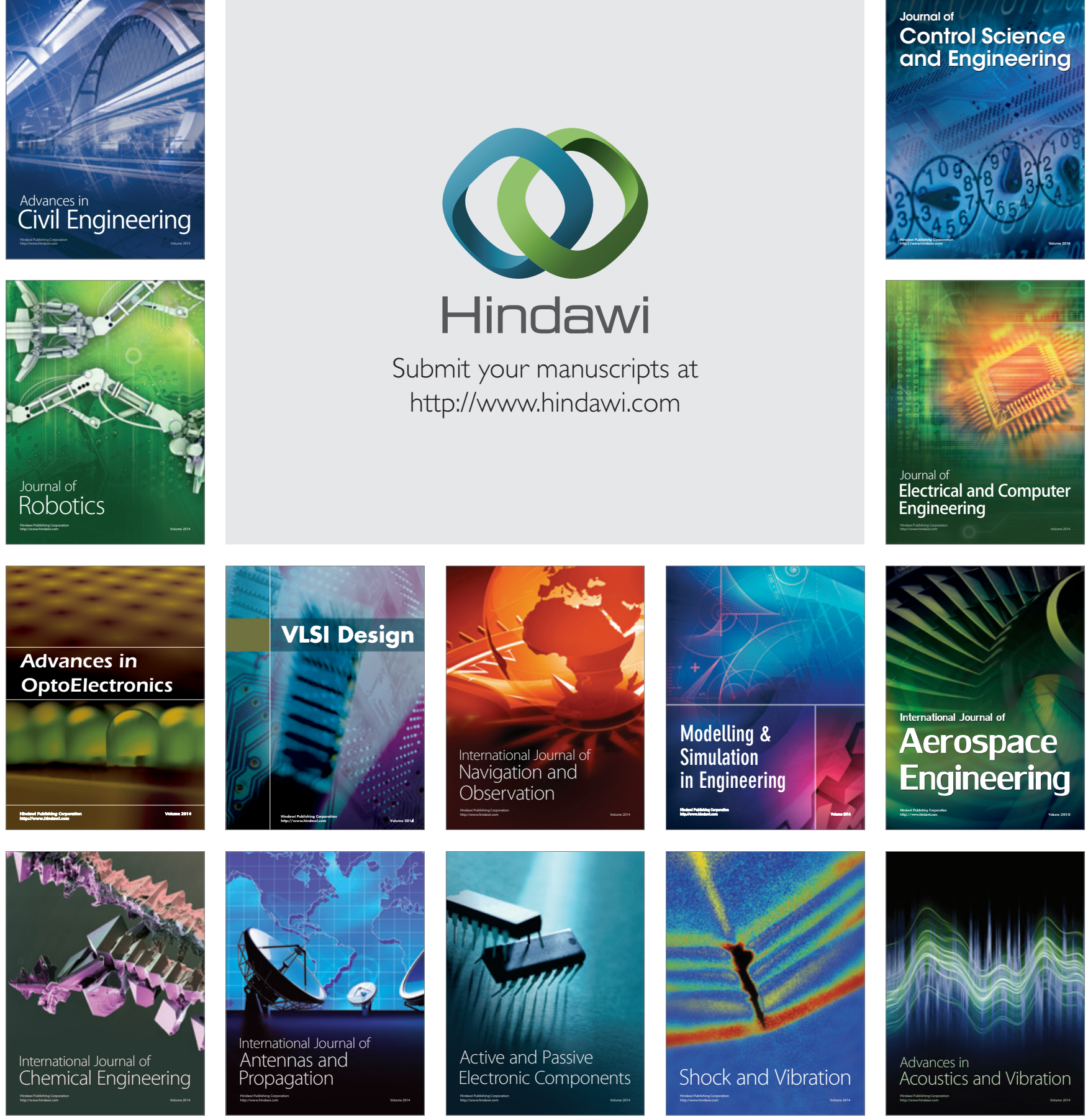